\title{
Development and Validation of a RP-HPLC Method for Assay of Atorvastatin and its Application in Dissolution Studies on Thermosensitive Hydrogel-Based Nanocrystals
}

\author{
Mallesh Kurakula ${ }^{1}$, Tariq R Sobahi ${ }^{1}$, AM El-Helw ${ }^{2}$ and Magdy Y Abdelaal ${ }^{1,3^{*}}$ \\ ${ }^{1}$ Polymer Research Lab, Department of Chemistry, Faculty of Science, ${ }^{2}$ Department of Pharmaceutics, Faculty of Pharmacy, \\ King Abdulaziz University, Jeddah, Saudi Arabia, ${ }^{3}$ Department of Chemistry, Faculty of Science, Mansoura University, $35516-$ \\ Mansoura, Egypt
}

*For correspondence: Email: myabdelaal@gmail.com, abdelaal@mans.edu.eg; Tel: +966-500096707

\begin{abstract}
Purpose: To develop and validate a novel reverse phase high performance liquid chromatographic (RP-HPLC) method for the quantification of atorvastatin in thermosensitive hydrogel-based nanocrystal formulation.

Method: Chromatographic identification was achieved on $C 18(5 \mu \mathrm{m})$ column using acetonitrile and $0.025 \mathrm{M}$ potassium dihydrogen ortho-phosphate buffer $\mathrm{pH} 5(45: 55 \mathrm{~V} / \mathrm{V})$ as mobile phase, at a flow rate of $1.5 \mathrm{~mL} / \mathrm{min}$ and using photo diode array detector (PDA) at $246 \mathrm{~nm}$. The developed HPLC method was validated according to International Conference on Harmonisation (ICH) Q2(R1) guidelines and applied to dissolution studies on atorvastatin thermosensitive hydrogel-based nanocrystal formulation, using Lipitor ${ }^{\circledR}$ as standard.

Results: Determination was successfully achieved with good peak resolution from atorvastatin nanocrystals and a commercial formulation brand (Lipitor ${ }^{\circledR}$ tablets) without interference of polymer or excipients. The retention time of atorvastatin was $4.5 \mathrm{~min}$ and drug response was linear in the range of $0.1-0.5 \mu \mathrm{g} / \mathrm{mL}$ with a correlation coefficient of 0.9995. Precision was determined to be between 0.16 0.61 percent relative standard deviation (\% RSD) for the analyzed samples. The limit of detection and of quantification was 35.6 and $71.2 \mathrm{ng} / \mathrm{mL}$, respectively, which was 10 times higher than a previously reported method. The assay of atorvastatin nanocrystal and Lipitor $®$ gave 99.37 and $99.12 \%$ recovery, respectively. Dissolution studies showed atorvastatin release of 40 and $65 \%$ at 40 min from thermosensitive hydrogel nanocrystal formulation and Lipitor $\circledast$, respectively indicating sustained release.

Conclusion: The method is successfully validated and is specific, linear, precise, and accurate with good robustness. It is applicable to atorvastatin nanocrystal dissolution studies and is a promising quality control tool for atorvastatin analysis in nanoformulations and pharmaceutical dosage forms.
\end{abstract}

Keywords: Atorvastatin, Anticholestermic, Dissolution studies, Hydrogel, Nanocrystal, Thermosensitive

Tropical Journal of Pharmaceutical Research is indexed by Science Citation Index (SciSearch), Scopus, International Pharmaceutical Abstract, Chemical Abstracts, Embase, Index Copernicus, EBSCO, African Index Medicus, JournalSeek, Journal Citation Reports/Science Edition, Directory of Open Access Journals (DOAJ), African Journal Online, Bioline International, Open-J-Gate and Pharmacy Abstracts

\section{INTRODUCTION}

Atorvastatin [(3R, 5R)-7-[2-(4-fluorophenyl)-3phenyl-4-(phenylcarbamoyl)-5-propan-2-ylpyrrol1-yl]-3, 5-dihydroxyheptanoic acid] calcium is one of the seven often-administered statins, belonging to the anti-hyperlipidemic class of drugs [1]. The primary indication of atorvastatin is in the treatment of dyslipidemia, as it is a competitive inhibitor of 3-hydroxy-3-methyl- 
glutaryl-co enzyme A (HMG Co-A) reductase [24]. Atorvastatin is administered orally in 10,20 , 40 , or $80 \mathrm{mg}$ dose per day $[5,6]$. The drug is reported to have poor solubility leading to low absolute and systemic bioavailability of about 14 and $30 \%$, respectively $[7,8]$. Modified or prolonged release delivery systems for atorvastatin are not available except for Selfnano emulsifying drug delivery systems (SNEDDS) [9]. Nanocrystals possess high entrapment efficiency, with enhanced solubility and drug bioavailability [10]. The release modification of drugs by incorporation of nanocrystals into a thermosensitive polymer matrix is very innovative, and assay of atorvastatin along with other excipients within nanoformulation is challenging as well [11].

Estimation of atorvastatin using ultraviolet spectroscopy was reported [12]. Most analytical methods are developed using RP-HPLC for the estimation of atorvastatin alone in tablets [13] or simultaneous by with simvastatin [14], amlodipine [15], atenolol [16] and also in nanoemulsion [17]. Few chromatographic methods to estimate new or specific drugs in novel drug delivery systems such as proliposomes are reported $[18,19]$. However, majority of the reported methods for estimation of atorvastatin lack specificity/ selectivity and are tedious or expensive. Moreover, none of these methods have been employed for dissolution studies of atorvastatin. Dissolution studies have emerged not only as important tool in formulation development or to characterize the drug product performance but also for quality control of finished products.

Therefore, the present work aims to develop a fast, simple, precise reversed phase high performance liquid chromatographic method for estimation of atorvastatin in thermosensitive hydrogel-based nanocrystal formulation and for dissolution studies on the drug formulation. The developed chromatographic parameters were validated in accordance with ICH-Q2(R1) guidelines [20].

\section{EXPERIMENTAL}

\section{Chemicals}

Atorvastatin calcium (API) was a gift from Jamjoom Pharma, Saudi Arabia. The acetonitrile, methanol, ammonium acetate, potassium dihydrogen orthophosphate, orthophosphoric acid, and sodium hydroxide used in the study were of analytical grade and purchased from
Sigma Aldrich, USA. HPLC-grade water was obtained from the SD-labostar (3 TWF-UV) water purification system. Filters with pour size of 0.2 , 0.45 and $0.5 \mu \mathrm{m}$ (Waters, Milford, USA) were used for the filtration of the mobile phase and the sample solutions, respectively.

\section{Method development}

Atorvastatin solubility within a suitable solvent system at a particular $\mathrm{pH}$ plays a vital role in HPLC method development. To optimize conditions, various permutations and combinations of solvent systems were tried for the mobile phase using organic solvents such as methanol, acetonitrile, and aqueous potassium dihydrogen orthophosphate as a buffer solution. The various combinations of solvent systems tried in the chromatographic method development are shown in Table 1(a).

\section{Evaluation of system suitability parameters}

System suitability variables and their optimization are vital in RP liquid chromatographic method. The individual parameters were validated in triplicate injections $(n=3)$ of standard solution (1 $\mu \mathrm{g} / \mathrm{mL}$ ) using Agilent series 1200 HPLC instrument with Eclipse $\mathrm{XDB}^{\circledR}$ column $5 \mu \mathrm{m}(4.6 \mathrm{x}$ $150 \mathrm{~mm}$ ). The optimized mobile phase used was Acetonitrile: $0.025 \mathrm{M}$ potassium dihydrogen orthophosphate $(\mathrm{pH} 5,45: 55(\mathrm{v} / \mathrm{v})$ in isocratic mode with a flow rate of $1.5 \mathrm{~mL} / \mathrm{min}$. Detection was recorded using 1260 infinite photo-diode array detector of $80 \mathrm{~Hz}$ at $25^{\circ} \mathrm{C}$.

\section{Preparation of buffer}

Potassium dihydrogen orthophosphate $1.7 \mathrm{~g}$ was dissolved in $400 \mathrm{~mL}$ of HPLC-grade water and adjusted to $\mathrm{pH} 5.0$ with $0.1 \mathrm{M}$ sodium hydroxide. The final volume was made up to $500 \mathrm{~mL}$ by HPLC-grade water and filtered under a vacuum using a $0.45 \mu \mathrm{m}$ membrane filter.

\section{Preparation of standard solution}

Atorvastatin calcium (100 mg) was transferred into a $100 \mathrm{~mL}$ A-grade volumetric flask and 25 $\mathrm{mL}$ of the mobile phase was added with sonication for about $5 \mathrm{~min}$ and made up to the required volume with the mobile phase to yield a solution with a concentration of $1 \mathrm{mg} / \mathrm{mL}$. The final solution was filtered under a vacuum using a $0.45 \mu \mathrm{m}$ membrane filter. The standard solutions were prepared in the concentration range of 0.1 - $0.5 \mu \mathrm{g} / \mathrm{mL}$ by serial dilutions of the stock solution. Triplicate injections (5 $\mu \mathrm{L}$ each) were made by an auto sampler for each concentration and analyzed under optimized chromatographic 
conditions. A calibration curve of the response (peak area) versus the concentration of the drug was plotted, and subjected to regression analysis.

\section{Preparation of thermosensitive hydrogel- based nanocrystals}

Atorvastatin calcium (about $40 \mathrm{mg}$ ) was dissolved in $2 \mathrm{~mL}$ of dimethyl sulfoxide and sonicated for $5 \mathrm{~min}$ to ensure complete drug solubility. The drug solution was dispersed in a premixed coarse suspension prepared by dissolving tween 80 and polyvinyl alcohol at a ratio of 25:75. The obtained suspension was centrifuged for $2 \mathrm{~min}$ at $9000 \mathrm{rpm}$, and homogenized at high pressure by an APV Micron Lab 40 homogenizer (APV systems, Germany). Homogenization was done initially at low pressure (500 bars) for 3 cycles and then followed by high pressure (1500 bars) for 20 cycles. The final suspension was vacuum-dried for 30 min under a nitrogen atmosphere and lyophilized to yield a stable dry powder.

Thermosensitive hydrogel was prepared by weighing and dissolving the required pluronic F127 in distilled water to obtain a concentration of $25 \%(\mathrm{w} / \mathrm{w})$. The calculated amount of lyophilized nanocrystal powder was incorporated into the gel matrix at the ratio of 1:5 under constant stirring in an ice bath until a clear solution was obtained. The final formulation exhibited sol and gel characteristics at 4 and 35 ${ }^{\circ} \mathrm{C}$, respectively [11].

\section{Analysis of nanocrystal formulation}

Formulation equivalent to $1 \mathrm{~g}$, was transferred into a volumetric flask having $3 \mathrm{~mL}$ methanol followed by sonication for about $15 \mathrm{~min}$ for the drug to dissolve completely. The test solution was filtered through a $0.5 \mu \mathrm{m}$ membrane filter and the solution was made up to the required volume with the mobile phase to obtain solutions with concentration in the range of $1-5 \mu \mathrm{g} / \mathrm{mL}$. A steady base line was recorded under an optimized chromatographic condition. The drug concentration was analyzed in triplicate $(n=3)$, and assay was subjected to a regression equation.

\section{Analysis of marketed product (Lipitor ${ }^{\circledR}$ )}

Ten tablets $\left(\right.$ Lipitor $\left.^{\circledR}\right)$ were accurately weighed and finely powdered. A portion of powder, equivalent to the weight of one tablet, was accurately weighed and transferred into $20 \mathrm{~mL}$ Agrade volumetric flask and $8 \mathrm{~mL}$ of mobile phase was added to it. The volumetric flask was sonicated for 20 min until there was complete dissolution of the atorvastatin. The content was made up to mark with mobile phase and then filtered through a $0.45 \mu \mathrm{m}$ nylon filter. Aliquots of The samples were diluted appropriately to obtain concentrations of atorvastatin in the range of linearity previously described and assayed.

\section{Method validation}

\section{Assay for nanocrystal formulations}

The assay developed for formulation must show atorvastatin within or at the extremes of the specified range $(80-120 \%)$. The proposed method should also be able to separate and estimate atorvastatin with regard to potential interference from the presence of excipients within the formulation.

\section{Accuracy}

The accuracy of the proposed method was determined by recovery studies. Three concentrations- low (10\%), medium (50\%), high $(100 \%)$ of the atorvastatin standard were added to the placebo. All solutions were prepared in triplicate $(n=3)$. For recovery studies, proportions of atorvastatin in nanocrystal formulation were made $1: 1$ by the addition of standard atorvastatin.

\section{Precision}

Intra-day assay precision (repeatability) and inter-day (intermediate) precision were determined. The analysis was performed for three concentration levels $0.1,0.3$, and $0.5 \mu \mathrm{g} /$ $\mathrm{mL}$ concentrations in triplicate. The \% RSD and standard error were calculated at each concentration level.

\section{Limit of detection and of quantification}

Detection and quantitation limits were determined by a signal-to-noise ratio method, using ratios of $3: 1$ and $10: 1$, respectively, such that elicited response was accurately and reliably measured.

\section{Robustness and ruggedness}

The robustness of the developed method was studied by small deliberate changes being made in chromatographic conditions such as $\mathrm{pH}$ and mobile-phase ratio at two levels: $\pm 0.2 \%$. The chromatogram was recorded, and the change in retention time was recorded at each level. The method's ruggedness was assessed by comparison of intra-day and inter-day assay 
results of atorvastatin performed by two analysts in the same laboratory.

Dissolution studies for atorvastatin
nanocrystals

Dissolution was evaluated according to United States Pharmacopeia (USP) [21] apparatus 2 paddle set-up (PharmaTest PT-DT7, USA) using phosphate buffer ( $\mathrm{pH}$ 7.4).Lyophilized powders, equivalent to $40 \mathrm{mg}$ of atorvastatin were weighted accurately and filled in $00 \#$ gelatin capsules. The dissolution test was performed at $37{ }^{\circ} \mathrm{C}$, with $0.5 \%$ sodium lauryl sulfate at $50 \mathrm{rpm}$. Aliquots $(5 \mathrm{~mL})$ were withdrawn at $5,10,20,30$, 45 and $60 \mathrm{~min}$, respectively. The withdrawn sample was replaced immediately with fresh dissolution medium to maintain sink conditions, and the samples filtered with $0.45 \mu \mathrm{m}$ membrane filter, mixed with an equal volume of mobile phase, and analyzed by the developed HPLC method. The dissolution profiles were constructed and compared with that of Lipitor $®$ as control.

\section{Statistical analysis}

All results are depicted as mean \pm standard deviation ( $S D, n=3)$. Statistical significance of difference was evaluated using one-way ANOVA at a probability level of 0.05 using Minitab 17.

\section{RESULTS}

\section{Method development}

The optimal conditions considered for mobile phase were $45: 55 \mathrm{v} / \mathrm{v}$ ratio of acetonitrile to 0.025 $\mathrm{M}$ potassium dihydrogen orthophosphate buffer at $\mathrm{pH} 5$, which gave a sharp symmetric peak at a flow rate of $1.5 \mathrm{~mL} / \mathrm{min}$. Sample of $5 \mu \mathrm{L}$ was injected in triplicate $(n=3)$ and the different optimization trials of chromatographic parameters are depicted in Table 1.

\section{Specificity and stress stability}

The results of the stress studies indicated the specificity of the developed method. After atorvastatin solution had been exposed to stress conditions, an assay for individual stress condition was performed. The chromatogram showed a well-resolved peak for atorvastatin and its degradation products after exposure. The stability studies, moreover, proved that the developed formulation was stable up to $14-15$ $\mathrm{h}$, which is sufficient to complete the analytical procedure.

\section{Linearity}

The method's linearity was calculated by leastsquare linear regression analysis of the calibration curve. The constructed calibration curve was found to be linear over the concentration range of $0.1-0.5 \mu \mathrm{g} / \mathrm{mL}$. The resulting calibration curve followed the equation $y$ $=15979 \mathrm{x}-44.49$ with a linear regression coefficient of 0.9995 were $y$ is the peak area based on three parallel measurements and $x$ is the concentration $(\mu \mathrm{g} / \mathrm{ml})$ of atorvastatin standard solution.

Table 1: Chromatographic method development conditions: A: Acetonitrile and B: $0.025 \mathrm{M}$ potassium dihydrogen orthophosphate buffer of $\mathrm{pH} 5.0$

\begin{tabular}{llll}
\hline Condition & $\begin{array}{l}\text { Ratio of } \\
\text { A:B } \\
(\mathbf{v} / \mathbf{v})\end{array}$ & $\begin{array}{l}\text { Atorvastatin } \\
\text { retention time } \\
(\mathbf{m i n})\end{array}$ & $\begin{array}{l}\text { Tailing } \\
\text { factor }\end{array}$ \\
\hline $\mathbf{1}$ & $20: 80$ & 11.5 & 1.191 \\
$\mathbf{2}$ & $30: 70$ & 9.2 & 1.159 \\
$\mathbf{3}$ & $40: 60$ & 6.5 & 1.065 \\
$4^{*}$ & $45: 55$ & 4.7 & 1.045 \\
\hline${ }^{*}$ The selected mobile phase is highlighted
\end{tabular}

\section{Assay for nanocrystal formulation and marketed product}

The assay for atorvastatin in formulated the nanocrystal and Lipitor ${ }^{\circledR}$ was distinct and showed a good separation and peak resolution at expected retention time [Figure $1(\mathrm{a}, \mathrm{b})]$. The content of atorvastatin was found to be $99.30 \%$ \pm 0.27 and $99.50 \% \pm 0.24 \mathrm{RSD}$, indicating that the method showed good recovery and precision, towards the nanocrystal formulations and for the marketed product $\left(\right.$ Lipitor $^{\circledR}$ ) respectively (Table 2).

Table 2: Analysis of Atorvastatin in thermosensitive hydrogel-based nanocrystals and in Lipitor ${ }^{\circledR}$

\begin{tabular}{llcccc}
\hline Formulation & Analyte & $\begin{array}{c}\text { Label claim } \\
(\mathbf{m g})\end{array}$ & $\begin{array}{c}\text { Amount found }(\mathbf{m g}, \mathbf{n}= \\
\mathbf{3}) \pm \mathbf{S D}\end{array}$ & $\begin{array}{c}\text { Actual drug found } \\
\mathbf{( \% )}\end{array}$ & \% RSD \\
\hline Nanocrystal & Atorvastatin & 40 & $39.72 \pm 0.108$ & 99.30 & 0.27 \\
Lipitor $^{\circledR}$ & Atorvastatin & 40 & $39.82 \pm 0.097$ & 99.55 & 0.24 \\
\hline
\end{tabular}



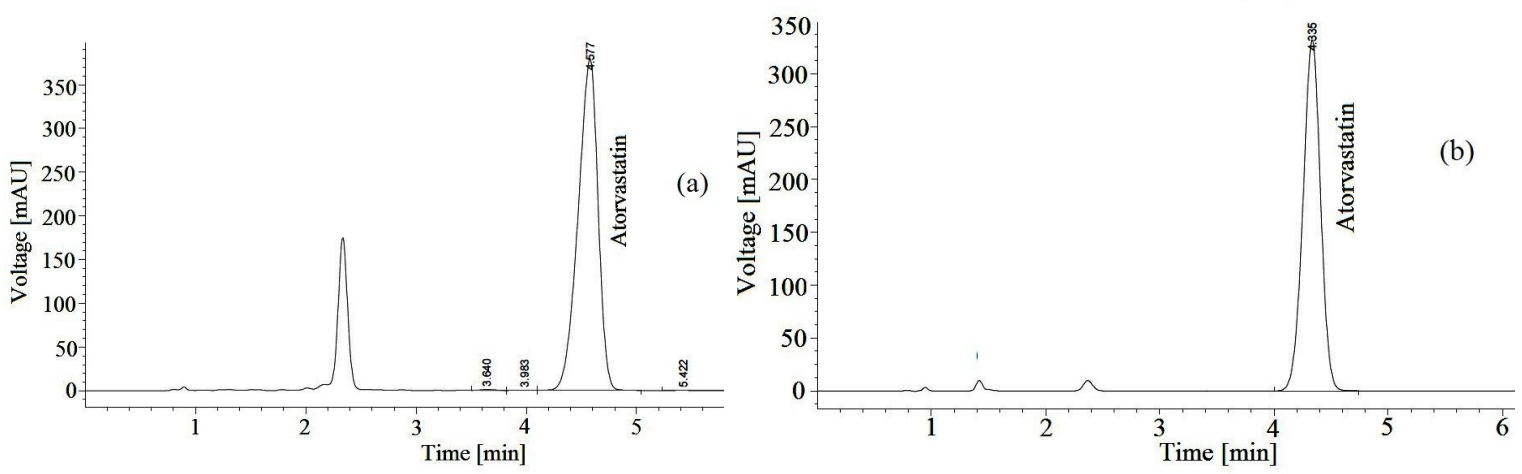

Figure 1: A typical chromatogram obtained after (a) analysis of nanocrystal formulation (b) Lipitor ${ }^{\circledR}$

Table 3: Accuracy results by recovery studies of the proposed method

\begin{tabular}{lccc}
\hline Drug concentration spiked & $\begin{array}{c}\text { Measured concentration } \\
(\mathbf{n}=\mathbf{3}) \pm \mathbf{S D}\end{array}$ & Recovery (\%) & \% RSD \\
\hline $10(0 \%)$ & $9.90 \pm 0.061$ & 99 & 0.61 \\
$15(50 \%)$ & $14.91 \pm 0.024$ & 99.40 & 0.16 \\
$20(100 \%)$ & $19.95 \pm 0.017$ & 99.75 & 0.58 \\
\hline
\end{tabular}

\section{Accuracy}

The developed method afforded recovery of 99 $\%$ to $99.75 \%$ for atorvastatin standard solutions after spiking with a known concentration of atorvastatin. In all the three levels, the calculated $\%$ RSD were found to be less than $1 \%$, indicating that the developed method was accurate and precise (Table 3).

\section{Precision}

Intraday-assay precision was found to be less than $1 \%$ RSD for all the samples on all three days. The \% RSD results for intra-day and interday precision are depicted in (Table 4).

\section{Limit of detection and of quantification}

The limits of detection and quantification were 35.6 and $71.2 \mathrm{ng} / \mathrm{mL}$, respectively.

\section{Robustness and ruggedness}

There was no significant change in the peak area in the comparison of intra-day and inter-day assay results which were performed by two analysts in the same laboratory. Slight changes in $\mathrm{pH}$ of buffer $\mathrm{pH} 5 \pm 0.2$ and in organic phase ratio within mobile phase, \pm 0.2 , did not affect the retention time, indicating that the method was robust.

\section{Dissolution - comparison of atorvastatin nanocrystal with Lipitor ${ }^{\circledR}$}

The developed method proved its application in dissolution studies of the atorvastatin nanocrystal formulation in comparison with Lipitor ${ }^{\circledR}$. The dissolution studies were helpful in determining the cumulative release (\%) from nanocrystal formulation. The results are plotted in Figure 2.

\section{DISCUSSION}

Atorvastatin nanocrystal formulation was successfully prepared by one of the top-down technologies using a high-pressure homogenization technique [10]. The formulation was optimized using a combination of Tween 80 as a surfactant and polyvinyl alcohol as a polymer stabilizer and further lyophilized. A reported RP-

Table 4: Precision results of the proposed method

\begin{tabular}{|c|c|c|c|c|c|c|c|c|}
\hline \multirow{2}{*}{$\begin{array}{l}\text { Atorvastatin } \\
(\mu \mathrm{g} / \mathrm{mL})\end{array}$} & \multicolumn{2}{|c|}{$\begin{array}{l}\text { Day 1 } \\
(n=3)\end{array}$} & \multicolumn{2}{|c|}{$\begin{array}{c}\text { Day 2 } \\
(\mathrm{n}=3)\end{array}$} & \multicolumn{2}{|c|}{$\begin{array}{l}\text { Day 3 } \\
(n=3)\end{array}$} & \multicolumn{2}{|c|}{$\begin{array}{l}\text { Intermediate Precision } \\
(\mathrm{n}=3)\end{array}$} \\
\hline & $\begin{array}{l}\text { Peak Area } \\
\pm \text { SD }\end{array}$ & $\%$ RSD & $\begin{array}{l}\text { Peak Area } \\
\pm \text { SD }\end{array}$ & $\%$ RSD & $\begin{array}{l}\text { Peak Area } \\
\pm \text { SD }\end{array}$ & $\%$ RSD & $\begin{array}{c}\text { Peak Area } \\
\pm \text { SD }\end{array}$ & $\%$ RSD \\
\hline 0.1 & $1440.2 \pm 1.41$ & & $1442.2 \pm 0.95$ & & $1444.4 \pm 2.26$ & & $1445.3 \pm 2.2$ & 0.15 \\
\hline 0.3 & $47402+1.10$ & 0.02 & $47432 \pm 0.9$ & 0.01 & $4745.3+2.01$ & 0.04 & $47442+21$ & 0.04 \\
\hline 0.5 & $7913.5 \pm 1.5$ & 0.01 & $7913.4 \pm 1.6$ & 0.02 & $7921.9 \pm 1.98$ & 0.02 & $7917.3 \pm 2.2$ & 0.02 \\
\hline
\end{tabular}




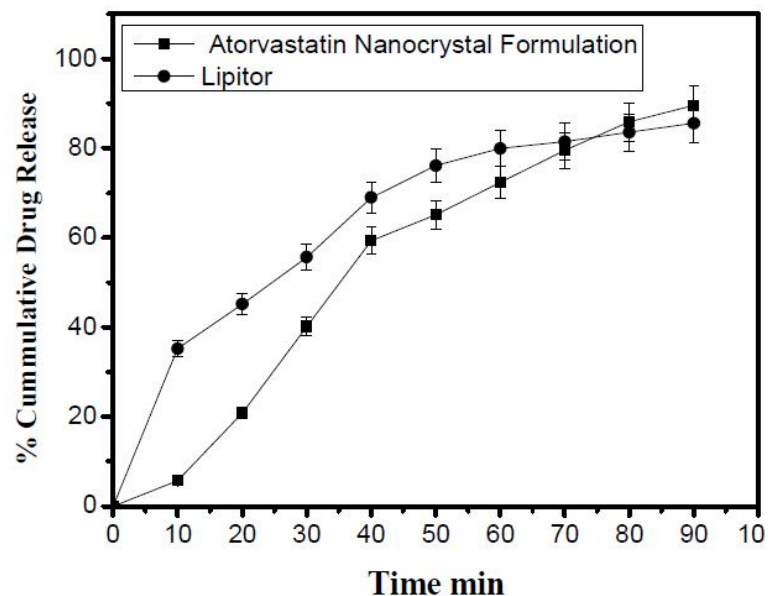

Figure 2: Dissolution profile of atorvastatin nanocrystal formulation in comparison to Lipitor $^{\circledR}$

HPLC method for nanoformulation [17] was considered but obtained results were not specific and precise because of high \% RSD and retention time. Therefore, we developed and validated a simple, rapid RP-HPLC method using an eclipse $\mathrm{XDB} \otimes$ column and mobile phase of different compositions and flow rate. C18 column was chosen for its high hydrophobicity over $\mathrm{C} 8$, so that atorvastatin was eluted faster at a lower flow rate and retention time. Acetonitrilewater and methanol-water systems were tested as solvent systems, but were not considered, because of poor peak resolution and separation of atorvastatin. Therefore, different buffers such as ammonium acetate and potassium dihydrogen orthophosphate at different molarity and $\mathrm{pH}$ were tried and tested. The mobile phase with potassium dihydrogen orthophosphate as a buffer in combination with acetonitrile was tried in order to optimize the chromatographic method. Acetonitrile ratio, change in $\mathrm{pH}$, and buffer molarity influenced both the retention time and peak symmetry. It was evident that atorvastatin was degraded on exposure to highly acidic, and alkali conditions. The selected mobile phase with $\mathrm{pH}$ adjustment indicated high selectivity and was capable of resolving atorvastatin from other excipients. The slight changes in the $\mathrm{pH}$ of the buffer solution and the organic phase ratio showed no marked changes in the retention time, which demonstrated that the method developed as robust. The release of the atorvastatin was much prolonged in the nano crystal due to the nanocrystal encapsulation within the pluronic hydrogel matrix. The percentage cumulative release of atorvastatin was $40 \%$ when compared to $65 \%$ of Lipitor $\otimes$ at $40 \mathrm{~min}$. The data proved the extent of sustained release of atorvastatin from nanocrystal formulation. The developed RPHPLC method was validated according to $\mathrm{ICH}$ guidelines, exemplifying its major application in dissolution studies of atorvastatin nanocrystals formulation.

\section{CONCLUSION}

Quantification of atorvastatin in thermosensitive polymer-based nanocrystals has been successfully achieved using current validated RP-HPLC method. The method is simple, rapid, precise, reproducible and accurate. An excellent resolution exists between peak area and drug concentration. The method developed has been successfully used to perform dissolution testing of atorvastatin within thermosensitive hydrogelbased nanocrystal formulation. The current method can be conveniently used as a quality control tool for the analysis of atorvastatin in nanoformulations and other pharmaceutical dosage forms.

\section{ACKNOWLEDGEMENT}

Mr Mallesh Kurakula is thankful to King Abdulaziz University for doctoral scholarship, and also grateful to the Dean, Faculty of Pharmacy of the same university for providing facilities to carry out this work.

\section{REFERENCES}

1. Acton QA. Antihyperlipidemic agents: Advances in research and application. Scholarly Editions, 2012.

2. Rundek $T$, Naini A, Sacco $R$, Coates K, Dimauro $S$. Atorvastatin decreases the coenzyme Q10 level in the blood of patients at risk for cardiovascular disease and stroke. Arch. Neurol. 2004; 61: 889-892.

3. Kawamoto S, Kawamura T, Miyazaki Y, Hosoya T. Effects of atorvastatin on hyperlipidemia in kidney disease patients. Nihon Jinzo Gakkai Shi. 2007; 49: 41-48.

4. Conde K, Vergara- Jimenez MBR, Newton RS, Fernandez ML. Hypocholesterolemic actions of atorvastatin are associated with alterations on hepatic cholesterol metabolism and lipoprotein composition in the guinea pig. J. Lipid Res. 1996; 37: 2372-2382.

5. Posvar EL, Radulovic LL (Jr), Cilla DD. Tolerance and pharmacokinetics of single-dose atorvastatin, a potent inhibitor of HMG- CoA reductase, in healthy subjects. J. Clin. Pharmacol. 1996; 36: 728-731.

6. Lennernas $H$. Clinical pharmacokinetics of atorvastatin. Clin. Pharmacokinet. 2003; 42: 1141-1160.

7. Corsini A, Bellosta S, Davidson MH. Pharmacokinetic interactions between statins and fibrates. Am. J. Cardio. 2005; 96: 44-49.

8. Jr. Cilla DD, Whitfield LR, Gibson DM, Sedman AJ, Posvar EL. Multiple-dose pharmacokinetics, 
pharmacodynamics, and safety of atorvastatin, an inhibitor of HMG-COA reductase, in healthy subjects. Clin. Pharmacol. Ther. 1996; 60: 687-695.

9. Miryala $V$, Kurakula $M$. Self-nano emulsifying drug delivery systems (SNEDDS) for oral delivery of atorvastatin -formulation and bioavailability studies. J. Drug Deliv. Therap. 2013; 3: 131-142.

10. Keck CM, Muller RH. Drug nanocrystals of poorly soluble drugs produced by high pressure homogenisation. Eur. J. Pharm. Biopharm. 2006; 62: 3-16.

11. Lin Z, Gao W, Hu H, Ma K, He B, Dai W, Wang X, Wang $J$, Zhang $X$, Zhang $Q$. Novel thermo-sensitive hydrogel system with paclitaxel nanocrystals: High drug-loading, sustained drug release and extended local retention guaranteeing better efficacy and lower toxicity. J. Control. Release. 2014; 174: 161-170.

12. Ghanty S, Sadhukhan N, Mondal A. Development and validation of a UV-spectrophotometric method for quantification of atorvastatin in tablets. J. Pharma. Sci. Tech. 2012; 2: 34-40.

13. Stanisz B, Kania L. Validation of HPLC method for determination of atorvastatin tablets and for monitoring stability in solid phase. Acta Pol. Pharm. 2006; 63: 471-476.

14. Novakova L, Satinsky D, Solich P. HPLC methods for the determination of simvastatin and atorvastatin. Trends Anal. Chem. 2008; 27: 352-367.

15. Manzoor A, Manohara YN, Ravi MC. RP-HPLC method development and validation for simultaneous estimation of atorvastatin calcium and amlodipine besylate. Int. J. Chem. Tech. Res. 2012; 4: 337-345.

16. Gupta KR, Wadodkar AR, Wadodkar SG. Validated Reverse Phase HPLC method for simultaneous estimation of atorvastatin and Atenolol in tablets. Pharm. Lett. 2011; 3: 393-403.

17. Mustafa G, Azeem A, Ahmad FJ, Khan ZI, Shakeel F, Talegaonkar S. Stability-indicating RP-HPLC method for analysis of atorvastatin in bulk drug, marketed tablet and nanoemulsion formulation. J. Chil. Chem. Soc. 2010; 55: 184-188.

18. Kurakula M, Mohd AB, Samhuidrom Rao P, Diwan PV. Estimation of prednisolone in proliposomal formulation using RP -HPLC method. Int. J. Res. Pharm. Biomed. Sci. 2011; 2: 663-1669.

19. Kurakula M, Mohd AB, Rao PA, Diwan PV. Estimation of piroxicam in proliposomal formulation using $R P$ HPLC method. Int. J. Chem. Anal. Sci. 2011; 2: 11931196.

20. International Conference on Harmonization (ICH) 2003. $\mathrm{ICH}$ Harmonized Tripartite guideline. Validation of Analytical Procedures: Text and Methodology Q2 (R1) Current Step 4 version. Parent Guideline dated 27 October 1994. (Complementary Guideline on Methodology dated 6 November 1996; incorporated in November 2005).

21. The United States Pharmacopeia and National Formulary USP 34-NF 29; The United States Pharmacopeial Convention, Inc.: Rockville, MD, 2011. 